\title{
Neuronal and BBB damage induced by sera from patients with secondary progressive multiple sclerosis
}

\author{
PATRIZIA PROIA ${ }^{1 *}$, GABRIELLA SCHIERA $^{2 *}$, GIUSEPPE SALEMI $^{3}$, PAOLO RAGONESE $^{3}$, \\ GIOVANNI SAVETTIERI ${ }^{3}$ and ITALIA DI LIEGRO ${ }^{2,4}$ \\ ${ }^{1}$ Dipartimento di Studi Giuridici, Economici, Biomedici, Psicosociopedagogici delle Scienze Motorie \\ e Sportive, ${ }^{2}$ Dipartimento di Scienze Biochimiche, ${ }^{3}$ Dipartimento Universitario di Neuroscienze Cliniche, \\ ${ }^{4}$ Dipartimento di Biologia Cellulare e dello Sviluppo, Università degli Studi di Palermo, Palermo, Italy
}

Received July 13, 2009; Accepted August 14, 2009

DOI: 10.3892/ijmm_00000287

\begin{abstract}
An important component of the pathogenic process of multiple sclerosis (MS) is the blood-brain barrier (BBB) damage. We recently set an in vitro model of $\mathrm{BBB}$, based on a three-cell-type co-culture system, in which rat neurons and astrocytes synergistically induce brain capillary endothelial cells to form a monolayer with permeability properties resembling those of the physiological BBB. Herein we report that the serum from patients with secondary progressive multiple sclerosis (SPMS) has a damaging effect on isolated neurons. This finding suggests that neuronal damaging in MS could be a primary event and not only secondary to myelin damage, as generally assumed. SPMS serum affects the permeability of the BBB model, as indicated by the decrease of the transendothelial electrical resistance (TEER). Moreover, as shown by both immunofluorescence and Western blot analyses, BBB breaking is accompanied by a decrease of the synthesis as well as the peripheral localization of occludin, a structural protein of the tight junctions that are responsible for BBB properties.
\end{abstract}

\section{Introduction}

Multiple sclerosis (MS) is a neurodegenerative disease characterized by focal inflammatory demyelination and glial scar formation. The pathogenic mechanism of MS is multifactorial $(1,2)$ and heterogeneous, both in terms of clinical course and neuropathological appearance (3). However, it is

Correspondence to: Profesor Italia Di Liegro, Dipartimento di Scienze Biochimiche, Via del Vespro 129, 90127 Palermo, Italy E-mail: diliegro@unipa.it

${ }^{*}$ Contributed equally

Key words: multiple sclerosis, brain cell cultures, in vitro models of blood-brain barrier, neuronal cell death, transendothelial electrical resistance accepted to consist of inflammatory and neurodegenerative phases (4), where demyelination should produce partially reversible clinical deficits that can remit, due to limited remyelination, while axonal degeneration produces permanent non-remitting clinical damage (5).

It is also assumed that the nervous system inflammation is initiated by autoreactive, myelin-specific $\mathrm{T}$ cells that permeate the blood-brain barrier and trigger a series of events leading to destruction of the myelin sheet (6). According to this view, axonal loss is considered secondary to inflammation and demyelination. However, it is becoming increasingly evident that extensive axonal damage already occurs at early stages of MS (7-9): axons could be sensitive to proteases, inflammatory cytokines and other molecules, produced by either activated immune cells or glial cells (10).

It has been found that neurofilament components (11), as well as other proteins of the cytoskeleton are costantly modified in MS patients during the entire course of the disease, thus confirming continuous axonal damage.

Although the exact cause of early axonal damage in MS remains elusive, it has been suggested that unknown factors present in the cerebrospinal fluid (CSF) from MS patients can induce neuronal apoptosis in cultured neurons $(12,13)$. In addition, neuronal apoptosis has been described in both cortical MS lesions (14) and in a rat model of MS [experimental autoimmune encephalomyelitis, EAE (15)].

Disruption of the blood-brain barrier is a hallmark of MS pathogenesis, possibly due to alterations of the tight junctions (TJs) that normally seal brain capillary endothelial cells together, thus impeding the paracellular flux of molecules across the endothelial cell layer. It has been recently reported that, although the highest level of disruption (affecting $40 \%$ of vessels) can be observed in active lesions, TJ disruption is also apparent in inactive lesions (23\% of vessels). Moreover, $\mathrm{TJ}$ disruption is accompanied by serum protein leakage across the BBB (16). A central role in BBB disruption might be played by astrocytes. Immunohistochemical analyses have revealed that several hypertrophic astrocytes are present at the rim of chronic active lesions and that these astrocytes produce chemokines, such as monocyte chemoattractant protein-1 (MCP-1) and interferon $\gamma$-inducible protein-10 (IP-10), as well as their receptors, CCR2 and CXCR3 (17). 
Factors produced by astrocytes (18) might induce migration/ activation of microglia and/or macrophages, and also lead to BBB disruption.

In this study, we report that in the serum from patients with secondary-progressive multiple sclerosis factors are present that induce neuronal cell death and cause alteration of permeability in a BBB model system.

\section{Materials and methods}

Patient recruitment and informed agreement. After accurate visiting and diagnosis, or control visit, the patients were informed of the ongoing research which was aimed at understanding the cellular and molecular mechanisms that underlie the pathology. Accurate explanations and further information were also given about the forms to be filled in and signed, in case of agreement to contribute to the research. All the procedures were done according to the Decree Law No. 196/03 (Arts. 7 and 13) that concerns protection of patients' privacy in the data processing and according to the World Medical Association Declaration of Helsinki.

Animals. Wistar rats (Stefano Morini, San Polo d'Enza, Italy) were housed in the institutional animal care facility of the Department of 'Biologia Cellulare e Sviluppo' (University of Palermo, Palermo, Italy), under direction of a licensed veterinary who approved the protocols. Procedures involving animals were conducted according to the European Community Council Directive 86/609, OJL 358 1, December 12, 1987. The number of animals used, as well as their suffering, has been reduced as much as possible. All protocols have been approved by the Ethics Committee of the University of Palermo.

Cell culture treatment and vitality assay. Neurons were purified from fetal rat cortices at the 16th day of gestation and cultured in serum-free Maat medium (MM) (19), on laminin $\left(2.5 \mu \mathrm{g} / \mathrm{cm}^{2}\right)$, as previously described (20). Astrocytes were purified from brain cortices of 2-day-old rats, as described by Cole and de Vellis (21), and cultured on fibronectin, in DME/Ham's F12 (2:1), supplemented with 10\% (v/v) heatinactivated fetal calf serum, up to half-confluence. RBE4.B immortalized rat brain microvessel cells (kind gift of Dr F. Roux, under the permission of Neurotech SA, Orsay, France) (22) were plated on collagen I $\left(2 \mathrm{mg} / \mathrm{cm}^{2}\right)$ and maintained in DME-Ham's F-12 (2:1), supplemented with $10 \%$ (v/v) heatinactivated fetal calf serum, $2 \mathrm{mM}$ glutamine, up to halfconfluence.

In order to set the $\mathrm{BBB}$ in vitro model, we used the transwell system described elsewhere (23-25). Briefly, neurons were cultured on laminin at the bottom of the wells of the companion plates, and fed with MM for 5 days. Afterwards, the porous inserts, on which astrocytes (adhering to the outer side of the porous membrane, on fibronectin) had been cultured for $4 \mathrm{~h}$, were wedged into the wells. After 2 more days, RBE4.B brain capillary endothelial cells (BCECs) were plated onto the inner surface of the insert membrane, on collagen IV. The entire system was then fed with MM for 5 days, before treatment.

For the analysis of the effects of MS patient serum, neuronal cell cultures were treated since the beginning with either control sera from healthy volunteers or with sera from patients with secondary progressive multiple sclerosis (SPMS), at a final concentration of $10 \%(\mathrm{v} / \mathrm{v})$. The BBB three-cell type model was instead treated with $10 \%(\mathrm{v} / \mathrm{v})$ serum for $24 \mathrm{~h}$ only.

Cell death was analyzed by staining the cells with a mixture of the fluorescent DNA-binding dyes, acridine orange (AO) and ethidium bromide (EB), each at a concentration of $100 \mu \mathrm{g} /$ $\mathrm{ml}$ in PBS, as previously described (26).

Permeation experiments across the BCEC monolayer were started by substituting the feeding medium in the upper (donor) chamber with an identical volume of MM, in which serum (from SPMS patients or healthy volunteers) had been dissolved, at the final concentration of $10 \%(\mathrm{v} / \mathrm{v})$.

After $24 \mathrm{~h}$, the medium in both chambers was substituted with an equal volume of fresh MM, and the variation of transendothelial electrical resistance (TEER) was monitored, as described below.

Immunofluorescence. Cells were fixed with $96 \%$ ethanol, on ice, for $10 \mathrm{~min}$ and permeabilized for $5 \mathrm{~min}$ with $0.1 \%$ Triton $\mathrm{X}-100$, in PBS. Afterwards, they were incubated with goat polyclonal anti-occludin N19 antibodies (Santa Cruz, CA, USA). The secondary antibodies were anti-goat IgGs, conjugated to fluoresceine (Santa Cruz). The samples were also stained for DNA by treating with Vectashield mounting medium for fluorescence, containing 4'-,6-diamino-2-phenylindole (DAPI; Vector Laboratories, Youngstown, OH, USA). Cells were finally observed with an Olympus BX-50 microscope (Olympus Italia s.r.l., Segrate, Italy), equipped with Vario Cam B/W camera (Nikon Instruments s.p.a., Calenzano, Italy).

Western blot analyses. Cells were homogenized in homogenization buffer $(0.32 \mathrm{M}$ sucrose; $50 \mathrm{mM}$ sodium phosphate buffer, $\mathrm{pH}$ 6.5; $50 \mathrm{mM} \mathrm{KCl}, 0.5 \mathrm{mM}$ spermine; $0.15 \mathrm{mM}$ spermidine; $2 \mathrm{mM}$ EDTA, and $0.15 \mathrm{mM}$ EGTA), containing the protease inhibitors aprotinin $(2 \mu \mathrm{g} / \mathrm{ml})$, antipain $(2 \mu \mathrm{g} / \mathrm{ml})$, leupeptin $(2 \mu \mathrm{g} / \mathrm{ml})$, pepstatin A $(2 \mu \mathrm{g} / \mathrm{ml})$, benzamidine (1.0 $\mathrm{mM})$ and phenylmethylsulfonyl fluoride $(1.0 \mathrm{mM})$, all purchased from Sigma-Aldrich. Proteins (20 $\mu \mathrm{g}$ of total cell extracts) were separated by electrophoresis on denaturing $10 \%$ polyacrylamide slab gels (SDS-PAGE) and immunoblotted as described elsewhere (27). The membranes were immunostained with goat polyclonal anti-occludin N19 antibodies (Santa Cruz).

TEER measurement. TEER measurements were done by using an EVOM epithelial voltom meter, equipped with an STX2 electrode (World Precision Instruments, Berlin). In parallel with sample measurements, we also recorded the resistance of inserts bearing only the collagen IV and fibronectin substrata (blank values). The average of the blank values was subtracted from the resistance reading across the BCEC layer, in order to obtain the true resistance due to BCECs.

\section{Results}

We previously found that both neurons $(24,27,28)$ and astrocytes $(23,24)$ influence the ability of endothelial cells to 

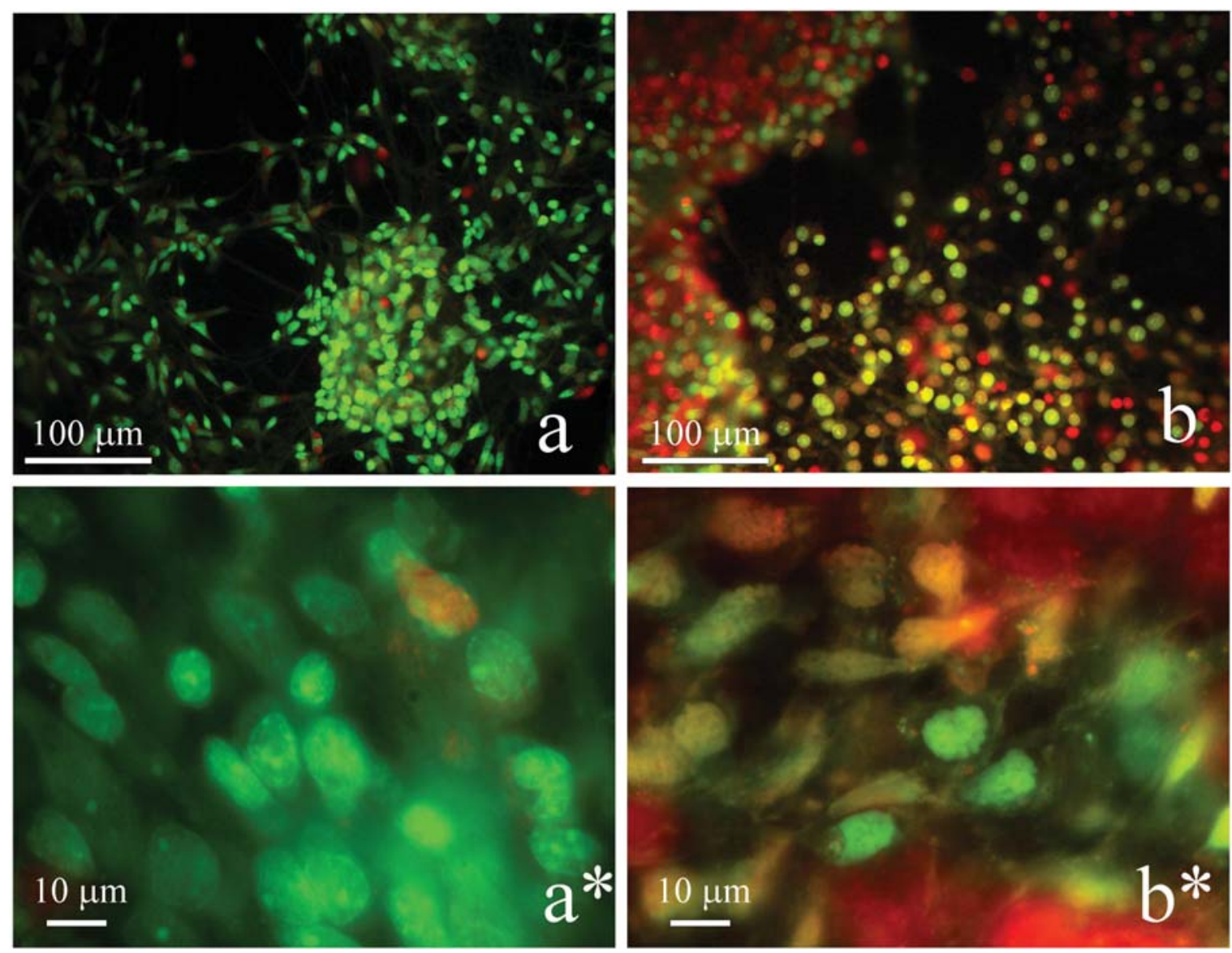

Figure 1. Induction of neuronal cell death by serum from secondary-progressive multiple sclerosis patients. Neurons were cultured for 5 days in Maat medium, containing $10 \%(\mathrm{v} / \mathrm{v})$ serum from either healthy volunteers (a and $\mathrm{a}^{*}$ ) or SPMS patients ( $\mathrm{b}$ and $\mathrm{b}^{*}$ ). At the end of treatment, cells were stained with a combination of the fluorescent DNA-binding dyes acridine orange and ethidium bromide, $100 \mu \mathrm{g}$ each/ml in PBS. Cells were observed in an Olympus BX-50 microscope, equipped with Vario Cam B/W camera.
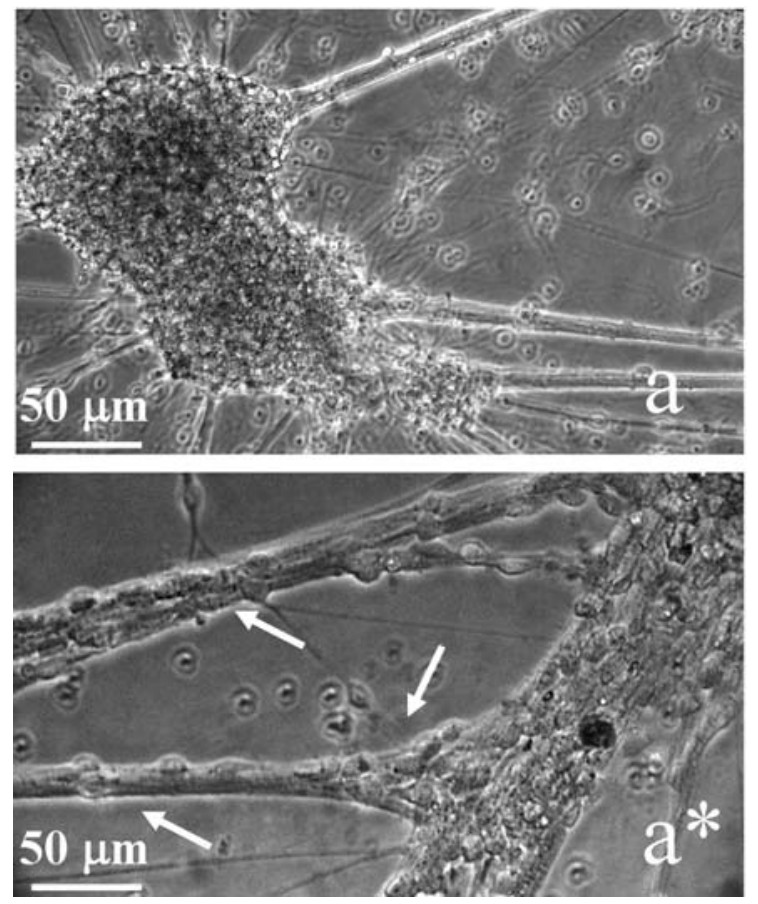

Figure 2. Phase-contrast microscopy recording of the morphological appearance of neurons, cultured for 15 days, in Maat Medium containing $10 \%(\mathrm{v} / \mathrm{v})$ serum from either healthy volunteers (a) or SPMS patients $\left(\mathrm{a}^{*}\right)$. The arrows point to abnormally thick bundles of neurites. form a barrier with properties resembling those of BBB. In the present study, we used an already described BBB in vitro model $(23,24)$ to investigate whether the serum from patients with secondary progressive multiple sclerosis (SPMS) (29) caused any alteration of the neuronal vitality and morphology, and/or any BBB damage. We analyzed first whether a $24 \mathrm{~h}$ treatment with SPMS serum (10\% in MM) might induce neuronal death. Neurons were stained with a mixture of acridine orange (AO) and ethidium bromide (EO). The differential uptake of these two dyes allows identification of viable and non-viable cells by fluorescence microscopy: normal nuclei in alive cells appear bright green, while apoptotic nuclei in dead cells appear bright orange/red and, in many cases, even fragmented into apoptotic bodies. As shown in Fig. 1, neurons treated with serum from healthy volonteers have green nuclei (Fig. 1a and $\mathrm{a}^{*}$ ), while cells treated with SPMS serum are clearly damaged (Fig. $1 b$ and $b^{*}$ ).

Moreover, phase-contrast microscopy showed that morphology of neurites was also affected by treatment with SPMS (Fig. 2a*), respect to control cells (Fig. 2a). The most peculiar observation was the increased diameter of the bundles of neurites, which appear thicker in SPMS-treated cells (Fig. 2a*).

Next, we investigated the possibility that the SPMS serum induces damage of the in vitro BBB model. We used a three cell type-coculture system $(23,24)$, that includes neurons, 

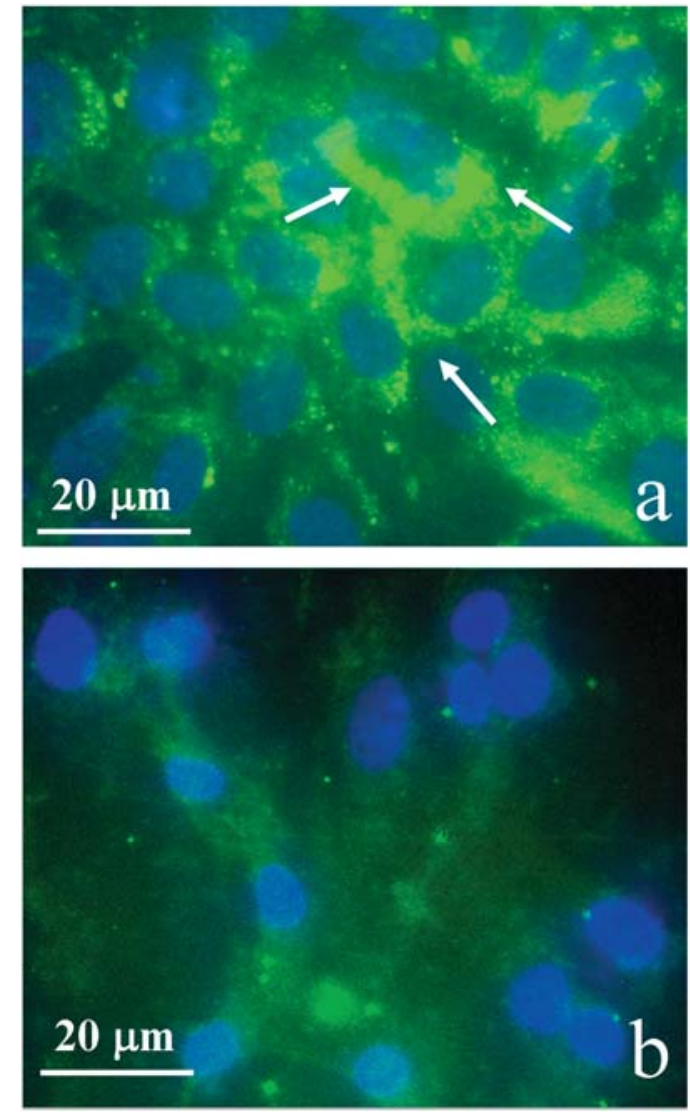

Figure 3. Immunostaining of occludin in RBE4.B brain capillary endothelial cells, cultured for 5 days with both cortical neurons and astrocytes, and then also treated for $24 \mathrm{~h}$ with either control serum (a) or SPMS (b). Cells were immunostained with goat polyclonal anti-occludin N19 antibody, as described in Materials and methods.

astrocytes and brain capillary endothelial cells (BCECs). BCECs were cultured inside the inserts, on collagen IV, in the presence of both neurons and astrocytes, and then treated with either serum from healthy controls (Fig. 3a), or SPMS serum (Fig. 3b), for $24 \mathrm{~h}$. Then cells were immunostained for occludin, one of the main structural proteins of the tight junctions (TJs), that seal endothelial cells together in the physiological BBB. As shown in Fig. 3, SPSM serum-treated cells (Fig. 3b), showed a severe decrease of peripherical immunofluorescent occludin, compared to cells treated with control serum (Fig. 3a). In agreement with this observation, Western blot analysis of BCECs, treated as described above, showed that the two main bands expected for occludin (60and $48-\mathrm{kDa}$, respectively) $(24,27,30,31)$ disappeared in SPMS-treated cells (Fig. 4).

Finally, the whole BBB in vitro model was tested by measuring the transendothelial electrical resistance, in each condition. We found that the treatment with SPMS serum caused a significant $(\mathrm{p}<0.005)$ decrease of TEER (Fig. 5).

\section{Discussion}

In this study, we report that serum from secondary-progressive multiple sclerosis patients induces cell death in cultured neurons and causes a severe decrease of the transendothelial electrical resistance in a BBB in vitro model.

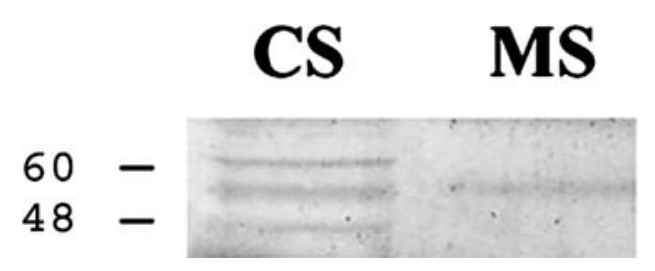

Figure 4. Western blot analysis of total lysates from RBE4.B brain capillary endothelial cells, cultured for 5 days with both cortical neurons and astrocytes, and then also treated for $24 \mathrm{~h}$ with either control serum (CS) or SPMS serum (MS). Proteins were immunostained with goat polyclonal anti-occludin N19 antibodies.

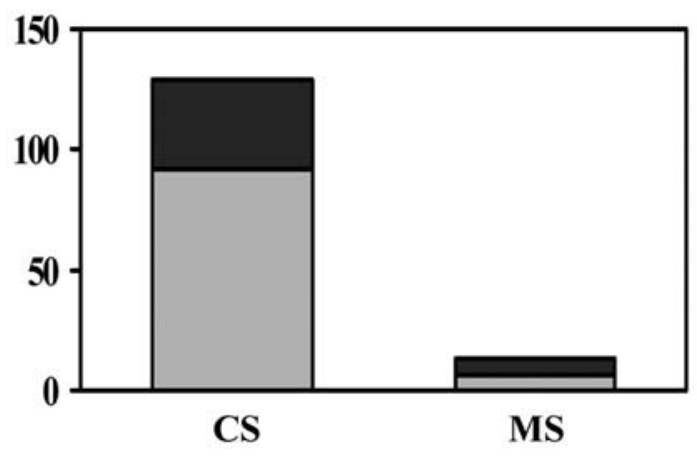

Figure 5. Transendothelial electrical resistence (TEER) of endothelial cell layers co-cultured for 5 days with neurons and astrocytes and then also treated for $24 \mathrm{~h}$ with either control serum (CS) or SPMS serum (MS). The grey bars represent means of 7 different experiments. Standard deviations are also shown (black bars). The difference between the means was highly significant $(\mathrm{p}<0.005)$.

The studies concerning neurons themselves clearly showed a profound effect on cell vitality. We observed that the neurite morphology was severely changed; the neurite bundles appeared much ticker in the SPMS-treated neurons, thus suggesting an alteration of the concentration and/or localization of certain factor(s) involved in bundling. Even if we cannot yet say which factors might be involved, the effect is quite evident. An effect of the SPMS serum on the permeability of an in vitro model of $\mathrm{BBB}$ was also found.

We previously reported that RBE4.B brain capillary endothelial cells (BCECs), cultured on collagen IV, form a barrier with $\mathrm{BBB}$ permeability properties, when co-cultured with astrocytes and/or neurons. Herein, we used this model to test the effects of SPMS serum. We chose two criteria to evaluate possible BBB damage: i) expression and peripheral localization of occludin. This protein has been reported to be a marker of TJ maturation, and TJs are of the most importance for the establishment of the BBB function, because they seal cells together, thus abolishing the paracellular flux of molecules and ions; ii) the transendothelial electrical resistance (TEER), measured across the BCEC monolayer, after treatment with sera from either healthy volunteers or SPMS patients. TEER is a consequence of the existence of a tissue barrier, which opposes the free exchange of ions across a given epithelium/ endothelium.

According to both criteria, a BBB alteration was evident: i) occludin almost disappeared, as concluded on the basis of both Western blot analyses and immunofluorescence; ii) 
TEER was significantly reduced respect to controls, when the BBB model was treated with SPMS serum.

These findings are in agreement with the fact that, in certain clinical studies of MS, leakage into the serum of brain proteins has been reported, thus suggesting BBB disruption $(32,33)$.

On the other hand, the fact that the SPMS serum has a direct damaging effect on isolated neurons is of high importance since it suggests that neuronal damage in MS could be a primary event and not only secondary to myelin damage, as generally assumed $(7,8)$.

\section{Acknowledgements}

This work was supported by Merck Serono S.p.A., and by the University of Palermo (fondi di Ateneo, Università degli Studi di Palermo). P. Proia was supported by Ph.D fellowship of the Università degli Studi di Palermo, Palermo, Italy. G. Schiera was supported by a postdoctoral fellowship by Università degli Studi di Palermo, Palermo, Italy.

\section{References}

1. Brassat D and Oksenberg JR: Genetics of multiple sclerosis. In: Molecular Bases of Neurodegeneration. Di Liegro I and Savettieri G (ed). Research Signpost, Kerala, pp43-59, 2005.

2. Olsson T, Jagodic M, Piehl F and Wallstrom E: Genetics of autoimmune neuroinflammation. Curr Opin Immunol 18: 643-649, 2006.

3. Lucchinetti C, Brück W, Parisi J, Scheithauer B, Rodriguez M and Lassmann H: Heterogeneity of multiple sclerosis lesions: implications for the pathogenesis of demyelination. Ann Neurol 47: 707-717, 2000.

4. Steinman L: Multiple sclerosis: a two-stage disease. Nat Immunol 2: 762-764, 2001.

5. van Horssen J, Bo L, Dijkstra CD and de Vries HE: Extensive extracellular matrix depositions in active multiple sclerosis lesions. Neurobiol Dis 24: 484-491, 2006.

6. McQualter JL and Bernard CCA: Multiple sclerosis: a battle between destruction and repair. J Neurochem 100: 295-306, 2007.

7. Ferguson B, Matyszak MK, Esiri MM and Perry VH: Axonal damage in acute multiple sclerosis lesions. Brain 120: 393-399, 1997.

8. Kuhlmann T, Lingfeld G, Bitsch A, Schuchardt J and Brück W: Acute axonal damage in multiple sclerosis is most extensive in early disease stages and decreases over time. Brain 125: 2202-2212, 2002.

9. Kim JH, Budde MD, Liang HF, Klein RS, Russell JH, Cross AH and Song SK: Detecting axon damage in spinal cord from a mouse model of multiple sclerosis. Neurobiol Dis 21: 626-632, 2006.

10. Bjartmar C, Wujek JR and Trapp BD: Axonal loss in the pathology of MS: consequences for understanding the progressive phase of the disease. J Neurol Sci 206: 165-171, 2003.

11. Malmestrom C, Haghighi S, Rosengren MD, Andersen O and Lycke J: Neurofilament light protein and glial fibrillary acidic protein as biological markers in MS. Neurobiology 61: 1720-1725, 2003.

12. Alcazar A, Regidor I, Masjuan J, Salinas M and AlvarezCermeno JC: Axonal damage induced by cerebrospinal fluid from patients with relapsing-remitting multiple sclerosis. J Neuroimmunol 104: 58-67, 2000.

13. Oren A, White L and Aasly J: Apoptosis in neurons exposed to cerebrospinal fluid from patients with multiple sclerosis or acute polyradiculoneuropathy. J Neurol Sci 186: 31-36, 2001.

14. Peterson JW, Bo L, Mork S, Chang A and Trapp BD: Transected neurites, apoptotic neurons, and reduced inflammation in cortical multiple sclerosis lesions. Ann Neurol 50: 389-400, 2001.
15. Meyer R, Weissert R, Diem R, Storch MK, de Graaf KL, Kramer B and Bahr M: Acute neuronal apoptosis in a rat model of multiple sclerosis. J Neurosci 21: 6214-6220, 2001.

16. Leech S, Kirk J, Plumb J and McQuaid S: Persistent endothelial abnormalities and blood-brain barrier leak in primary and secondary progressive multiple sclerosis. Neuropathol Appl Neurobiol 33: 86-98, 2007.

17. Tanuma N, Sakuma H, Sasaki A and Matsumoto Y: Chemokine expression by astrocytes play a role in microglia/macrophage activation and subsequent neurodegeneration in secondary progressive multiple sclerosis. Acta Neuropathol 112: 195-204, 2006.

18. Proia P, Schiera G, Mineo M, Ingrassia AM, Santoro G, Savettieri G and Di Liegro I: Astrocytes shed extracellular vesicles that contain fibroblast growth factor- 2 and vascular endothelial growth factor. Int J Mol Med 21: 63-67, 2008.

19. Cestelli A, Savettieri G, Ferraro D and Vitale F: Formulation of a novel synthetic medium for selectively culturing rat CNS neurons. Dev Brain Res 22: 219-227, 1987.

20. Savettieri G, Licata L, Catania C, Raneri R, Di Liegro I and Cestelli A: Synergistic effects of laminin and thyroid hormones on neuron polarity in culture. Neurol Rep 10: 1269-1272, 1999.

21. Cole R and de Vellis J: A Dissection and Tissue Culture Manual of the Nervous System. Alan R. Liss Inc., New York, 1989.

22. Roux F, Durieu-Trautmann O, Chaverot N, Claire M, Mailly P, Borre JM, Strosberg AD and Courad PO: Regulation of gammaglutamyl transpeptidase and alkaline phosphatase activities in immortalized rat brain microvessel endothelial cells. J Cell Physiol 159: 101-113, 1994.

23. Schiera G, Bono E, Raffa MP, Gallo A, Pitarresi GL, Di Liegro I and Savettieri G: Synergistic effects of neurons and astrocytes on the differentiation of brain capillary endothelial cells in culture. J Cell Mol Med 7: 165-170, 2003.

24. Schiera G, Sala S, Gallo A, Raffa MP, Pitarresi GL, Savettieri G and Di Liegro I: Permeability properties of a three-cell type in vitro model of blood-brain barrier. J Cell Mol Med 9: 373-379, 2005.

25. Schiera G and Proia P: In vitro models of blood-brain barrier: formation and functioning. In: Molecular Bases of Neurodegeneration. Di Liegro I and Savettieri G (ed). Kerala, pp 183-197, 2005.

26. Schiera G, Proia P, Alberti C, Mineo M, Savettieri G and Di Liegro I: Neurons produce FGF2 and VEGF and secrete them at least in part by shedding extracellular veiscles. J Cell Mol Med 11: 1384-1394, 2007.

27. Savettieri G, Di Liegro I, Catania C, Licata L, Pitarresi GL, D'Agostino S, Schiera G, De Caro V, Giandalia G, Giannola LI and Cestelli A: Neurons and ECM regulate occludin localization in brain endothelial cells. Neurol Rep 11: 1081-1084, 2000.

28. Cestelli A, Catania C, D'Agostino S, Di Liegro I, Licata L, Schiera G, Pitarresi GL, Savettieri G, De Caro V, Giandalia G and Giannola LI: Functional features of a novel model of Blood Brain Barrier: studies on permeation of test compounds. J Control Release 76: 139-147, 2001.

29. McDonald WI, Compston A, Edan G, Goodkin D, Hartung HP, Lublin FD, McFarland HF, Paty DW, Polman CH, Reingold SC, Sandberg-Wollheim M, Sibley W, Thompson A, van den Noort S, Weinshenker BY and Wolinsky JS: Recommended diagnostic criteria for multiple sclerosis: guidelines from the International Panel on the diagnosis of multiple sclerosis. Ann Neurol 50: 121-127, 2001.

30. Chen YH, Marzdorf C, Paul DL and Goodenough DA: COOH terminus of occludin is required for tight junction barrier function in early Xenopus embryo. J Cell Biol 138: 891-899, 1997.

31. Furuse M, Hirase T, Itoh M, Nagafuchi A, Yonemura S and Tsukita S: Occludin: a novel integral membrane protein localizing at tight junctions. J Cell Biol 123: 1777-1788, 1993.

32. Kwon EE and Prineas JW: Blood-brain barrier abnormalities in longstanding multiple sclerosis lesions. An immunohistochemical study. J Neuropath Exp Neurol 53: 625-636, 1994.

33. Bruck W, Bitsch A, Kolenda H, Brück Y, Stiefel M and Lassmann H: Inflammatory central nervous system demyelination: correlation of magnetic resonance imaging findings with lesion pathology. Ann Neurol 42: 783-793, 1997. 